\author{
Journal of Research \& Health \\ Social Development \& Health Promotion \\ Research Center \\ Vol. 8, No. 3, May \& Jun 2018 \\ Pages: 198- 209 \\ DOI: $10.29252 / j r h .8 .3 .198$ \\ Original Article
}

1. Department of Psychology, Faculty of Psychology and Educational Sciences, Semnan University, Semnan, Iran

2. Correspondence to: Department of Clinical Psychology, Faculty of Psychology and Educational Sciences, Semnan University, Semnan, Iran

Email: i_rahimian@semnan.ac.ir

3. Department of Educational Psychology, Faculty of Psychology and Educational Sciences, Semnan University, Semnan, Iran

Received: 12 Nov 2014

Accepted: 13 Jan 2015

How to cite this article: Safarzade $\mathrm{S}$, Rahimian Boogar I, Talepasand S. The role of demographical factors in prediction of successful termination of individual psychotherapy. $J$ Research Health2018; 8(3): 198- 209

\section{The role of demographical factors in prediction of successful termination of individual psychotherapy}

Somayeh Safarzade ${ }^{1}$, Isaac Rahimian Boogar ${ }^{2}$, Siavash Talepasand ${ }^{3}$

\begin{abstract}
Therapist related factors and also patient has many effects on phenomenon of successful termination of psychotherapy. Factor and growing a combination of these factors causes the patient to prematurely leave the psychotherapy sessions. This study aimed to investigate the role of demographic factors in predicting of successful termination of individual psychotherapy. Population study contained all of patients who referred to psychiatry and psychology clinics. Researcher made demographic questionnaire and outcome questionnaire were used to collect data. Stepwise regression analysis revealed that referral source, severity problem, income, access treatment, gender, level of education, therapist's level of education and type of therapy were predictors of successful termination and the final research model can predict $61 \%$ of the variance in the criterion for the successful termination of psychotherapy. There was no significant relationship between the cost of the treatment and the clinical diagnosis with successful termination of individual psychotherapy. The results showed that demographic factors are important predictors of successful termination of individual psychotherapy.
\end{abstract}

Keywords: Demographic, Drop Out, Psychotherapy, Successful, Termination

\section{Introduction}

Psychotherapy is formed as therapeutic interaction between trained professional and client, patient, family, couples or group. Psychotherapy is general term to treat mental disorders and other psychological distress in which wide range of techniques and strategies could be used based on the therapist's approach [1]. Psychotherapy process might be employed by psychiatrists, clinical psychologists, social workers, counselors or other care providers of mental hygiene. Nowadays, psychotherapy which is sometimes employed for the patients by using only psychological techniques and some other times with the use of drug therapy has become so popular and many individuals exploit it to treat psychological disorders which damage their personal and social life in great extent [2].

Research of recent decades indicated the effectiveness of psychotherapy. The quantitative and qualitative investigations of thousands of scientific studies in this 
field indicated that many patients who have undergone psychotherapy have achieved so many benefits. However, just a few numbers of patients with mental disorders are treated despite the existence of effective ways of drug therapy and psychotherapy [3].

A large number of who have significantly important and significant disorder and mental illness do not attend to psychiatric and psychological service centers and they do not get mental health services. Furthermore, many of those who attend to psychiatric and psychological treatments do not accept treatment recommendations and techniques and although they continue the treatment process completely their status will not be changed a lot [4]. There is another group among these individuals who have begun the psychotherapy process, but they leave the sessions much earlier than determined time [5]. Despite the fact that psychotherapy process has great effect on the improvement of patients with mental disorders, various studies across the world have indicated that many patients after the first session or after few sessions before termination of treatment process attempting to leave their therapy sessions [6-8].

Premature termination of psychotherapy is very common phenomenon in psychiatric and psychological clinics [9]. Approximately, half of all clients of psychiatric and psychological clinics attempting to leave treatment sessions before the determined time [10]. This number is very wide and broad. In some part of the world, the prevalence of this problem in psychiatric and psychological clinics has reported between $40 \%$ and $60 \%$ [6].Garfield believed that the premature terminator patient is someone who accepts the treatment psychotherapy process and at least attends one session but attempting to stop next sessions of treatment [8]. Wierzbicki $\&$ Pekarik believed that an premature treatment terminator individual is someone who makes unilateral decision to leave the treatment before termination of the process and achieving partial improvement [7]. Ogrodniczuk, Joyce, and Piper have considered premature termination as the patient's decision to end the treatment contrary to both therapist's recommendation and initial agreement made between patient and therapist [11]. In contrast, successful termination of psychotherapy is condition in which patients leave treatment after solving their problems and achieving primary goals of therapeutic process [12].

Various factors are involved in the treatment termination. According to importance of successful termination of treatment plan and also for reducing rate of patients with premature termination of psychotherapy investigating predictive factors in successful termination is has great importance for designing suitable interventions for their improvement. Findings of studies have indicated that demographic factors affect therapeutic results and successful termination of psychotherapy [9]. In some studies role of some demographic factors such as age, gender, type of mental disorder, level of education, income status, treatment access, treatment expense, referral source, therapist' education degree, severity of the patient's problem and type of received treatment have been investigated in relation to premature termination of psychotherapy [7,13,14]. Studies have been indicated that less age, male gender, having particular disorder, lower income, difficult access treatment, high treatment expense, referral to specialists in psychology and psychiatry by others, lower education degree of therapist and lower severity or moderation of the client's problem or discomfort have significant influence on premature termination of psychotherapy $[3,8,9,15]$. Psychiatric and psychological literature has put the termination of psychotherapy as the patient's authorizations at every stage of treatment except for the patients with high probability of self-damage or damaging others in which the necessity of informing legal authorities is definitive; however termination of psychotherapy before ending its process and patients' improvement is not only an unpleasant phenomenon for therapist, but also it is unfavorable to the patient [16]. Few studies have been done in 
this field in Iran and other parts of the world despite the great number of patients with premature termination of psychotherapy and the importance of this issue in clinical works $[9,15]$. As far as the authors of the present study have investigated the studies in the field of psychotherapy in Iran no studies have been found in the subject of the present study in Iran and also few studies have been conducted in other countries. The possible predictive patterns of this phenomenon have been identified poorly. It is hoped that the results of the present study can partly provide accurate comprehension of important demographic factors which have significant roles in termination process of psychotherapy. In case of lack of recognizing effective factors on occurrence of this phenomenon, we will confront with the increasing number of patients with premature termination of psychotherapy and this fact not only leads to discouragement, pessimism and disaffection of individuals for attending the psychotherapy sessions but also it has great effect on practical field and clinical work of psychologists and psychiatrists. Therefore, this study has been conducted to investigate the role of demographic factors in predicting of successful termination of individual psychotherapy

\section{Method}

The design of the present study is cross-sectional in which the predictive roles of gender, age, level of education, income, treatment access, referral source, treatment expense, therapist's level of education, the type of psychotherapy, the severity of the patient's problem or discomfort from the patient's view and clinical diagnosis on premature termination of psychotherapy have been investigated. Population study contained all of patients who referred to psychiatry and psychology clinics in Mashhad city during January 2013-2014. participant consisted of 317 individuals who were by convenience sampling method. Researcher made demographic questionnaire and outcome questionnaire scale were used to collect data. The inclusion criteria were considered as; referral to psychiatric and psychological clinics of Mashhad city, informed consent to participate in the research, having at least diploma degree, receiving at least five sessions of psychotherapy for participants who are receiving psychotherapy during research, lack of disorder and psychological problem history, lack of previous referral to the psychiatrists or psychologists and receiving one of the types of individual treatments as psychoanalysis, cognitivebehavioral and eclectic. The exclusion criteria of research consists of completing the research instruments incorrectly and also receiving one of the types of individual treatments except studied psychotherapy in this research. To perform the research process, it was referred to clinics, psychiatric and psychological centers of Mashhad, psychiatric and psychological clinic of Ibn Sina at Ibn Sina hospital, psychotherapy and counselling clinic of Astan Quds Razavi, Saba clinic, Counseling Center of Mashhad University of Medical Sciences and counseling center of Islamic Azad University of Mashhad after getting the necessary license from the faculty of psychology and education sciences at Semnan. The participants of the study were selected by considering the inclusion criteria of the research. In order to comply with ethical principles, abbreviated purpose of the study was explained to them and in case of receiving informed consent from the participants they were provided by questionnaires and they were asked to complete the instruments honestly. The data were analyzed by using SPSS-16.

Researcher-made questionnaire was developed to collect demographic information. Demographic questionnaire contains demographic information of participants such as age, gender, level of education, income status and type of disorder, access to treatment, cost of treatment, referral source, and therapist's education degree, the severity of problem from patient's point of view, clinical diagnosis and type of psychotherapy. Outcome Questionnaire (OQ $\left.{ }^{\circledR}-42.2\right)$ was 
used to assess the successful termination of psychotherapy. This scale was developed by Lambert, Lunnen, Umphress, Hansen, and Burlingame in 1994 to evaluate depression and anxiety, social-role functioning, and interpersonal relationships of patients who attend to psychotherapy sessions [17]. Results of several studies have indicated that this questionnaire has been very fruitful instrument in determining the effectiveness of psychotherapy and assessing the successful termination of psychotherapy [18]. In this questionnaire, the successful termination of psychotherapy has been considered as an important index of the effectiveness of psychotherapy [18]. The scale consists of 45 items that three dimensions of symptom distress of patient (22 items), social-role functioning (9 items), and interpersonal relationships (11 items) which are assessed in Likert-type scale from zero to four. The range of the scoring is from zero to 180 . Lower obtained score has been indication better process of psychotherapy and successful termination. Score of zero in this questionnaire indicates successful termination of psychotherapy, and score of 180 shows unsuccessful termination of psychotherapy. In a research by Lambert et al in 2012 Cronbach's alpha for this questionnaire was obtained 0.93 and its retest was 0.84 . Its concurrent reliability with symptom checklist-90, Beck's depression inventory, Taylor's Manifest Anxiety Scale, and State-Trait Anxiety Inventory was range of 0.64 to 0.88 for all correlations [19]. For the present study, Cronbach's alpha was obtained 0.95.

\section{Results}

The participants consisted of 146 (46.1\%) females and $171(53.9 \%)$ males. The age range of the participants was between 18 and 59 years old with the mean age of 32.91 and standard deviation of 8.94. Regarding level of education, Participants of the study consisted $103(32.5 \%)$ individuals with diploma degree, $97(30.6 \%)$ individuals with bachelor's degrees, 67 (21.1\%) with master's degrees, and $50(15.8 \%)$ with doctoral degrees. According to the treatment access; it was easily possible for
215 (67.8\%) individuals; in contrast access to treatment was associated them with great difficulties for $102(32.2 \%)$ individuals. The referral source of 205 (64.7\%) participants of the research was themselves and $70(22.1 \%)$ individuals were referred to the clinics by specialists of mental hygiene and relatives. The problem severity from the patient's point of view was ranked by 133 (42\%) individuals as low severity, $76(24 \%)$ individuals as high severity, 45 (14.2\%) individuals as very high severity, and 63 (19.9\%) individuals as infinite severity. The expense of one treatment session in all therapeutic stages was between 100 and 250 thousand rials for $189(56.6 \%)$ individuals, 250 and 400 thousand rials for $32(10.1 \%)$ individuals, 400 and 550 thousand rials for 59 (18.6\%) individuals, 550 and 700 thousand rials for $38(11.9 \%)$ individuals, and more than 700 thousand rials for $9(2.8 \%)$ individuals. The cost of treatment was evaluated by asking and requesting subjects to select the most suitable option in demographic questionnaire about expense for therapeutic sessions. The mean (standard deviation) of research participants was obtained 34.55 (19.68) generally for the variable of the treatment's cost. The type of treatment was eclectic for $123(38.8 \%)$ individuals, was cognitive-behavioral for 141 (44.5\%) individuals and was psychoanalysis $53(16.7 \%)$ individuals. 111 individuals (35\%) had anxiety disorder, 129 (40.7\%) individuals had depression disorder, 35 (11\%) individuals had phobia disorder, and 42 $(13.2 \%)$ individuals had personality disorder. Therapist's level of education and specialty among 317 individuals of the present study were as follows: $88(27.8 \%)$ individuals had master of psychology, 47 (14.8\%) individuals had master of counseling and guidance, 117 $(36.9 \%)$ individuals had doctor of psychology, $21(6.6 \%)$ individuals had doctor of counseling and $44(13.9 \%)$ therapists were psychiatrists. Also, the mean (standard deviation) of the successful termination variable was obtained $1.31(0.77)$. This variable has been investigated as a continuous variable that the 
increase or decrease of its score is intended in the present study due to the variability of sessions and the duration of treatment and using the outcome scale for assessing the successful termination of psychotherapy. Therefore, in the current study just the number of treatment sessions is not the determinant of successful termination but the improvement rate is more important indicator of treatment outcome. Table 1 present the correlation matrix between successful termination of psychotherapy and demographic variables of gender, age, level of education, income status, referral source, access to treatment, cost of treatment, therapist's level of education, type of psychotherapy, the severity of problem from the patient's point of view and clinical diagnosis.

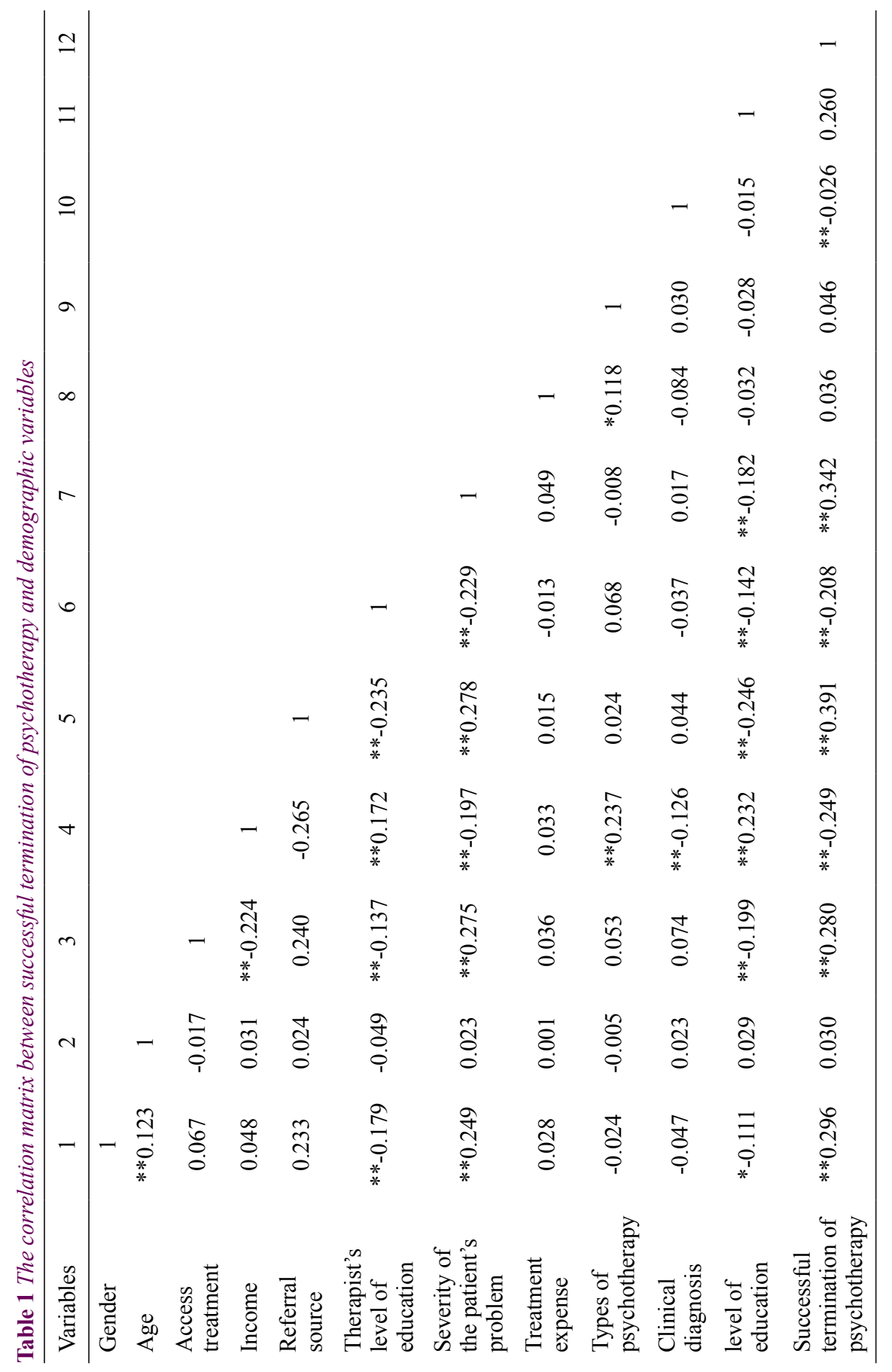


There is significant positive relationship between correlation coefficient of gender variable and successful termination of psychotherapy $\quad(\mathrm{r}<0.296, \quad \mathrm{p}<0.05), \quad$ access to treatment and successful termination of psychotherapy $(\mathrm{r}<0.280, \mathrm{p}<0.05)$. There is significant negative relationship between income status and successful termination of psychotherapy $(\mathrm{r}<-0.249, \mathrm{p}<0.05)$. There is significant positive relationship between referral source and successful termination of psychotherapy $(\mathrm{r}<0.391, \mathrm{p}<0.05)$. There is significant negative relationship between therapist's level of education and successful termination of psychotherapy $(\mathrm{r}<-0.208$, $\mathrm{p}<0.05)$. There is significant positive relationship between severity of the patient's problem and successful termination of psychotherapy $(\mathrm{r}<0.342, \mathrm{p}<0.05)$. There is significant negative relationship between level of educations and successful termination of psychotherapy $(\mathrm{r}<-0.260, \mathrm{p}<0.05)$. But the correlation coefficient was not significant between age and successful termination of psychotherapy $(\mathrm{r}<0.030, \mathrm{p}>0.05)$, cost of treatment and successful termination of psychotherapy $(\mathrm{r}<0.026, \mathrm{p}>0.05)$, types of type of treatments and successful termination of psychotherapy $(\mathrm{r}<0.046, \mathrm{p}>0.05)$, and clinical diagnosis and successful termination of psychotherapy $(\mathrm{r}<0.026, \mathrm{p}>0.05)$. The cost of treatment was not significantly related with any of the variables. Also, clinical diagnosis had only significant relationship with income status $(\mathrm{p}<0.05, \mathrm{r}<-0.126)$ and no significant relationship was found between this variable and other variables. Therefore, the scores of diagnosis and cost of treatment were eliminated from the regression equation. Stepwise regression was applied to predict the relationship between demographic variables and successful termination of psychotherapy. The results of regression analysis for demographic predictors of successful termination of psychotherapy have been presented in Table 2.

Table 2 Results of regression analysis for demographic predictors of successful termination of psychotherapy

\begin{tabular}{|c|c|c|c|c|c|c|c|}
\hline Steps & $\begin{array}{l}\text { Predictive } \\
\text { variables }\end{array}$ & $\begin{array}{l}\text { Multiple } \\
\text { R }\end{array}$ & $\mathrm{R}$ square & $\begin{array}{l}\text { Adjusted R } \\
\text { square }\end{array}$ & $\begin{array}{l}\text { Std. error } \\
\text { of estimate }\end{array}$ & $\mathrm{F}$ & Sig. \\
\hline 1 & Referral source & 0.558 & 0.312 & 0.309 & 0.62436 & 584.142 & 0.001 \\
\hline 2 & $\begin{array}{l}\text { Referral source }+ \text { severity of the } \\
\text { patient's problem }\end{array}$ & 0.685 & 0.496 & 0.466 & 0.56494 & 93.256 & 0.001 \\
\hline 3 & $\begin{array}{l}\text { Referral source }+ \text { severity of the } \\
\text { patient's problem }+ \text { income }\end{array}$ & 0.722 & 0.522 & 0.517 & 53716 & 34.317 & 0.001 \\
\hline 4 & $\begin{array}{l}\text { Referral source+severity of the } \\
\text { patient's problem }+ \text { income }+ \text { access } \\
\text { treatment }\end{array}$ & 0.746 & 0.556 & 0.550 & 51837 & 24.099 & 0.001 \\
\hline 5 & $\begin{array}{l}\text { Referral source }+ \text { severity of the } \\
\text { patient's problem }+ \text { income }+ \text { access } \\
\text { treatment }+ \text { gender }\end{array}$ & 0.767 & 0.588 & 0.581 & 50015 & 24.149 & 0.001 \\
\hline 6 & $\begin{array}{l}\text { Referral source }+ \text { severity of the } \\
\text { patient's problem }+ \text { income }+ \\
\text { access treatment }+ \text { gender }+ \text { level of } \\
\text { education }\end{array}$ & 0.783 & 0.613 & 0.605 & 48580 & 19.650 & 0.001 \\
\hline 7 & $\begin{array}{l}\text { Referral source }+ \text { severity of the } \\
\text { patient's problem }+ \text { income }+ \\
\text { access treatment }+ \text { gender }+ \text { level } \\
\text { of education }+ \text { education degree of } \\
\text { therapist }\end{array}$ & 0.789 & 0.622 & 0.614 & 48050 & 7.875 & 0.005 \\
\hline 8 & $\begin{array}{l}\text { Referral source }+ \text { severity of the } \\
\text { patient's problem }+ \text { income }+ \\
\text { access treatment }+ \text { gender }+ \text { level } \\
\text { of education }+ \text { education degree of } \\
\text { therapist }+ \text { types of psychotherapy }\end{array}$ & 0.793 & 0.629 & 0.619 & 47711 & 5.405 & 0.021 \\
\hline
\end{tabular}


As table above, in the first model that referral source was considered as predictor of successful termination of psychotherapy, adjusted value of this variable is obtained 0.309 which indicates that this variable could have explained $30 \%$ of variance of successful termination of psychotherapy. In the second model, referral source and severity of the problem were considered as predictor of successful termination of psychotherapy. The adjusted value of these variables is obtained 0.466, which indicates that these variables could have explained $46 \%$ of variance of successful termination of psychotherapy. In the third model, the adjusted value of referral source, severity of problem, and income status was obtained 0.51 , which is the indicator of the fact that these variables together predict 0.517 of variances in successful termination of psychotherapy. In the fourth model, the adjusted value of referral source, severity of the problem, income status and treatment access was obtained 0.550 , which indicates that these four variables could have explained $55 \%$ of variances of successful termination of psychotherapy. In the fifth model, the adjusted value of referral source, severity of the problem, income status, treatment access and gender was obtained 0.581 which indicates that these five variables together could have significantly explained $58 \%$ of variance of successful termination of psychotherapy. The adjusted value of referral source, severity of the problem, income status, treatment access, gender, and educations was 0.605 in the sixth model which indicates that these six variables could have explained $60 \%$ of variance of successful termination of psychotherapy. In the seventh model, the adjusted value of the referral source, severity of the problem, income status, treatment access, gender, level of education and the therapist's level of education was obtained 0.614 which indicates that seven variables of the present study could have explained $61 \%$ of variance of dependent variable and finally in the in the last model which consists of referral source, severity of the problem, income status, access to treatment, gender, level of education and type of psychotherapy, the adjusted value was obtained 0.619 which indicates that the final model of the present study could have explained $61 \%$ of variance of dependent variable. In Table 3, F-test (ANOVA) is presented for significance of regression.

Table 3 F-test (ANOVA) for significance of regression

\begin{tabular}{lccccc}
\hline Final model & Sum of squares & df & Mean square & F & Sig. \\
\hline Regression & 118.72 & 8 & 14.838 & 65.183 & 0.001 \\
Residual & 70.111 & 308 & 0.228 & & \\
Total & 188.812 & 316 & & & \\
\hline
\end{tabular}

$\mathrm{F}$ value and significance level were obtained respectively $(p<0.001, F=142.584)$ in the first model, $(\mathrm{p}<0.001, \mathrm{~F}=138.800)$ in the second model, $(p<0.001, F=113.791)$ in the third model, $(p<0.001, F=97.666)$ in the fourth model, $(\mathrm{p}<0.001, \mathrm{~F}=88.760)$ in the fifth model, $(\mathrm{p}<0.001, \mathrm{~F}=81.677)$ in the sixth model, $(\mathrm{p}<0.001, \mathrm{~F}=72.286)$ in the seventh model and $(p<0.001, F=65.183)$ in the eighth model. The result indicated that the regression value is in the significance level of 0.001 in all of models. Standardized and unstandardized coefficients of successful termination prediction through predictor variables in stepwise regression are presented in Table 4.

According to Table 4, referral source is the first variable which predicts successful termination of psychotherapy $(p<0.001, \beta=0.282)$, severity of problem is the second variable $(\mathrm{p}<0.001$, $\beta=0.249$ ), income status is the third variable $(p<0.001, \beta=-0.239)$, access to treatment is the fourth variable $(p<0.001, \beta=0.175)$, gender is the fifth variable $(p<0.001, \beta=0.178)$, level of education is the sixth variable $(p<0.001$, $\beta=-0.175)$, therapist's level of education is the seventh variable $(p<0.001, \beta=-0.109)$ and type of psychotherapy is the eighth variable $(\mathrm{p}<0.001, \beta=0.087)$. 
Table 4 Standardized and unstandardized coefficients of successful termination prediction through predictor variables in stepwise regression

\begin{tabular}{|c|c|c|c|c|c|c|}
\hline Step & $\begin{array}{l}\text { Constants } \\
\text { and predictor } \\
\text { variables }\end{array}$ & $\begin{array}{l}\text { Unstandardized } \\
\text { beta coefficient }\end{array}$ & Std. Error & $\begin{array}{c}\text { Standardized } \\
\text { beta } \\
\text { coefficient }\end{array}$ & $\mathrm{T}$ value & Sig. \\
\hline \multirow{9}{*}{$\begin{array}{l}\text { Eighth } \\
\text { (Final) }\end{array}$} & Constant & 0.149 & 0.186 & & 0.802 & 0.423 \\
\hline & Referral source & 0.422 & 0.064 & 0.282 & 6.645 & 0.001 \\
\hline & $\begin{array}{l}\text { Severity of } \\
\text { problem }\end{array}$ & 0.166 & 0.027 & 0.249 & 6.243 & 0.001 \\
\hline & Income & -0.100 & 0.017 & -0.239 & 5.838 & 0.001 \\
\hline & $\begin{array}{l}\text { Treatment } \\
\text { access }\end{array}$ & 0.289 & 0.062 & 0.175 & 4.634 & 0.001 \\
\hline & Gender & 0.276 & 0.059 & 0.178 & 4.694 & 0.001 \\
\hline & $\begin{array}{l}\text { level of } \\
\text { education }\end{array}$ & -0.114 & 0.027 & -0.157 & -4.186 & 0.001 \\
\hline & $\begin{array}{l}\text { therapist's level } \\
\text { of education }\end{array}$ & -0.063 & 0.022 & -0.109 & -2.939 & 0.004 \\
\hline & $\begin{array}{l}\text { Type of } \\
\text { psychotherapy }\end{array}$ & 0.094 & 0.040 & 0.087 & 2.325 & 0.021 \\
\hline
\end{tabular}

\section{Discussion}

In order to achieve the study's goal about investigation of the role of demographic predictors in successful termination of psychology the results of stepwise regression indicated that gender, age, level of education, income status, referral source, access to treatment, therapist's level of education, type of psychotherapy and the severity of problem in the patient's point of view affect successful termination of psychotherapy but cost of treatment and clinical diagnosis were not predictors of successful termination of psychotherapy.

The results of the present study indicated that income and level of education were predictors of successful termination of psychotherapy. The finding is consistent with findings of Wierzbicki and Pekarik, Baekeland and Lundwall and Flaskerud [14,20,21]. These studies found that income status and level of education influence the treatment's results and the process of treatment termination. It means that patients with higher level of education were more likely to attend treatment sessions and having successful termination of psychotherapy rather than patients with lower level of education and the higher the level of patients' income status have more the probability of successful termination of psychotherapy. Furthermore, the findings indicated that age and gender are predictors of successful termination of psychotherapy; however, the findings are inconsistent with studies of $[5,14,15,20]$. These researchers indicated that age and gender have not had influence on results of patients' treatment but the finding the current study is consistent with the results of studies of $[22,23]$. The other results of the present study were that the therapist's level of education is strong predictor of successful termination of psychotherapy. The finding is consistent with research of Reynolds [24]. In the present study, the severity of problem in the patient's point of view was another variable which was influential on the successful termination of psychotherapy and there was positive significant relationship between these two variables. The finding is consistent with the results of $[25,26]$ but it is not consistent with results of [27]. No significant relationship was found between the severity of problem in the patient's point of view and the level of patient's discomfort from the disease and successful termination of psychotherapy in the study of Persons et al [27]. As mentioned earlier, findings of the present study are consistent with some group of studies and inconsistent with other group of studies. In 
explaining of this consistency and inconsistency it could be stated that the differences regarding the predictive or non-predictive roles of demographic factors in successful termination of psychotherapy in different societies might have been due to the special sample features, different criteria and diagnostic instruments, several research designs, different source of information and cultural differences. Moreover, in explaining results of present study, as stated by McCallum et al, the existence of psychological pain and suffering is significant motivational factor for following and obeying the treatment recommendations until resolving the main problem [25]. Therefore, the higher the severity of the problem in the patient's points of view has more the probability of successful termination of psychotherapy.

In the present study no significant relationship was found between clinical diagnosis and successful termination of psychotherapy which is consistent with the findings of [28]. But it is not consistent with results of [22]. The cause of the inconsistency of results in different studies regarding the explanation of clinical diagnosis role in successful termination of psychotherapy could be due to high variability and heterogeneous categories of mental disorders and also different methodology of related studies. For example, in the study of (Clarkin, \& Levy) termination of psychotherapy process was investigated in patients with personality disorder; it was found that this disorder has great influence on quality of termination of psychotherapy [4]. In another study it was found that clinical diagnosis is strong predictor of successful termination of psychotherapy process and patients whose mental disorder was in axis I of mental disorders in the rate of premature termination of psychotherapy was higher in them than the group whose mental disorder was in other axes [29]. Furthermore, the findings of the present study indicated that treatment type is also predictor of successful termination of psychotherapy. The finding is consistent with the results of $[8,30]$. Regarding the treatment type the time factor is of great importance. In a research it was found that in psychoanalysis treatment which has long process and often lasts for years the prevalence of premature termination of psychotherapy is higher, in contrast to the cognitive-behavioral or eclectic treatments in which less number of sessions or time duration is spent for identification of the cause of problem and patient's discomfort and finally patient's improvement. Different therapeutic techniques and methods of each treatment approach are other contributing factors in different rate of successful termination of psychotherapy [7,31].

In the current study, referral source was also predictor of successful termination of psychotherapy and this finding is consistent with the results of the previous study [32] in this field. In explaining the obtained results it could be stated that referral source influence the achieved results in high level. It could be argued that patient who is directed toward treatment process would attend the treatment sessions more willingly than those whose referral source was others based on own tendency and desire and most probably they will get better results and they would be more pleased with the treatment and its process. Moreover, when the referral source is own self; it implies the high readiness of the individual for making changes which underlies the successful termination of psychotherapy.

The findings of the present study indicated that cost of treatment had no influence on successful termination of psychotherapy. The obtained result is inconsistent with results of [3] in which it has been stated that the expense of psychoanalysis services affects the completion of treatment process and successful termination of psychotherapy. The inconsistency of the findings in current study with the mentioned study could be due to the differences in statistic population and sample or differences in assessment methods of successful termination of psychotherapy. In the current study, considering the reference time of Iranian patients to the psychotherapy clinics at the height of the mental health problems, it could be presumed that due to the severity of the symptoms and increasing 
burden of disease, patients prefer to complete the treatment even with high cost.

Access to treatment had also significant positive correlation with successful termination of psychotherapy. It means that easier treatment access is more the probability of successful termination of psychotherapy. The obtained result is consistent with the result of [3]. In explaining the achieved result, it could be stated that the patient for whom treatment access is difficult after a few sessions will stop continuing the treatment process because of the path difficulties. It could be also argued that better access to treatment is the facilitator of execution of the therapeutic measures and finally the predictor of successful termination of psychotherapy.

Liu-Siefert et al believed that many factors have to contribute together to achieve successful termination of psychotherapy. The study's results of these researchers in 2005 indicated that premature termination of treatment sessions would lead to decrease of therapeutic results and increase of individual's disease, readmissions and decreases the probability of requesting for help by patients in future problems. According to Liu-Seifert, Adams, and Kinon readmission of individual make mental problems also economically will cause problems for individual, due to the fact that costs of psychological and psychiatric services are very high and sometimes the individual will be unable to repay the heavy costs [33]. According to results, it is suggested to conduct the current study in different populations, in order to determine influential on successful termination of psychotherapy in other populations and research samples. Furthermore, in the present study only the influential demographic factors on successful termination of psychotherapy were investigated so it is suggested that the role of other psychological and social factors in successful termination of psychotherapy can be investigated in future studies.

Despite the fact that the present study tried to be done carefully and accurately and also it contains helpful results in the field of psychotherapy but it had some limitations too. Its first limitation is that the method of present study is cross-sectional. The main feature of cross-sectional method is that data are gathered in short period of time in it and due to this fact recognizing cause and effect relationships would become limited. The second limitation is about sampling method in the current study which has been convenience sampling and this method of sampling led to the exclusion of so many patients with more various conditions who sometimes have singular treatment experiences. The third limitation is that the data of the research which has been obtained by using self-report questionnaires and using questionnaires has its own disadvantages. The participants of the study might not have been honest and answer the questions in such a way that actually it has not been true or they might not have been accurate enough in choosing the option and they have not chosen the option which is completely conforming their conditions and undoubtedly these type of answering will negatively influence the results of the study.

\section{Conclusion}

In the current study it was tried to investigate the most important demographic factors in occurrence of premature termination of psychotherapy. The research's results indicated that demographic factors of gender, age, level of education, income status, referral source, access to treatment, therapist's level of education, type of psychotherapy and the severity of the problem in patient's point of view influence the premature termination of psychotherapy.

The results of this study are expected to provide detailed understanding of this fact among people and especially those with mental problems and disorders that the effective and important factors during the sessions and psychotherapy process being observed and therapists and the individual step jointly through direction of treatment process and its progression, psychotherapy and attending the treatment sessions will be favorable and fruitful for the individual. 


\section{Acknowledgements}

The authors would like to thank and sincerely appreciate all staffs of psychiatric and psychological clinics of Ibn Sina hospital, psychotherapy and counselling clinic of Astan Quds Razavi, Saba clinic, Counseling Center of Mashhad University of Medical Sciences and counseling center of Islamic Azad University of Mashhad and all patients in the study who had full cooperation in the processes of the research.

\section{Contribution}

Study design: IRB, SS

Data collection and analysis: SS, ST, IRB

Manuscript preparation: SS, IRB

\section{Conflict of Interest}

The authors declare that they have no competing interests.

\section{Funding}

The author (s) received no financial support for the research, authorship and/or publication of this article.

\section{References}

1- Seligman ME. The effectiveness of psychotherapy: The consumer reports study. Am Psychol1995; 50(12): 965-74.

2- Kazdin AE. Evidence-based treatment and practice: new opportunities to bridge clinical research and practice, enhance the knowledge base, and improve patient care. Am Psychol2008; 63(3): 146-59.

3- Barrett MS, Chua W-J, Crits-Christopher P, Gibbons MB, Thompson D. Early withdrawal from mental health treatment: implications for psychotherapy practice. Psychotherapy (Chic)2008; 45(2): 247-67.

4- Clarkin JF, Levy KN. The influence of client variables on in psychotherapy. Lambert MJ, ed. Bergin and Garfield's handbook of psychotherapy and behavior change. New York:Wiley \& Sons; 2004.

5- Gonzalez A, Weersing VR, Warnick EM, Scahill LD, Woolston JL. Predictors of treatment attrition among an outpatient clinic sample of youths with clinically significant anxiety. Adm Policy Ment Health2011; 38(5): 356-67.

6- Hamilton S, Moore AM, Crane DR, Payne SH. Psychotherapy dropouts: differences by modality, license, and DSM-IV diagnosis. $J$ Marital Fam Ther2011; 37(3): 333-43.

7- Wierzbicki M, Pekarik G. A meta-analysis of psychotherapy dropout. Prof Psychol Res Pr1993; 24(2): 190-95.

8- Garfield SL. Research on patient variables in psychotherapy. In: Garfield SL, Bergin AE. Handbook of psychotherapy and behaviour. New York: Wiley and Sons; 1986.

9- Westmacott R, Hunsley J, Best M, Rumstein-McKean $\mathrm{O}$, Schindler D. Client and therapist views of contextual factors related to termination from psychotherapy: a comparison between unilateral and mutual terminators. Psychother Res2010; 20(4): 423-35.

10- Swift JK, Callahan J, Levine JC. Using clinically significant change to identify premature termination. Psychotherapy (Chic)2009; 46(3): 328-35.

11- Ogrodniczuk JS, Joyce AS, Piper WE. Strategies for reducing patient-initiated premature termination of psychotherapy. Harv Rev Psychiatry2005; 13(2): 57-70. 12- Lau AS, Weisz JR. Reported maltreatment among clinic referred children: Implications for presenting problems, treatment attrition, and long-term outcomes. J Am Acad Child Adolesc Psychiatry2003; 42(11): 1327-34.

13- Miller LM, Southam-Gerow MA, Allin Jr RB. Who stays in treatment? Child and family predictors of youth client retention in a public mental health agency. Child Youth Care Forum2008; 37(4): 153-70.

14- Swift JK, Greenberg RP. Premature discontinuation in adult psychotherapy: A meta-analysis. $J$ Consult Clin Psychol2012; 80(4): 547-59.

15- Edlund MJ, Wamg PS, Berglund PA, Katz SJ, Lin E, Kessler R. Dropping out of mental health treatment: Patterns and predictors among epidemiological survey respondents in the United States and Ontario. Am J Psychiatry2002; 159(5): 845-51.

16- Younggren JN, Fisher MA, Foote WE, Hjelt SE. A legal and ethical review of patient responsibilities and psychotherapist duties. Prof Psychol Res Pr2011; 42(2): 160-8.

17- Lambert MJ, Lunnen K, Umphress V, Hansen N, Burlingame GM. Administration and scoring manual of the outcomes questionnaire (OQ-45.1). Salt Lake City, Utah, IHC Center for Behavioral Healthcare Efficacy; 1994.

18- Kadera SW, Lambert MJ, Andrews AA. How much therapy is really enough: A session-by-session analysis of the psychotherapy dose-effect relationship. $J$ Psychotherapy Pract Res 1996; 5(2): 132-51.

19- Lambert M. The outcome questionnaire-45. Inte Sci Pra2012; 2(2): 24-7.

20- Baekeland F, Lundwall L. Dropping out of treatment: A critical review. Psychology Bull1975; 82(5): 738-83.

21- Flaskerud JH. The effects of culture-compatible intervention on the utilization of mental health services 
by minority clients. Community Ment Health J1986; 22(2): 127-41.

22- Olfson M, Mojtabai R, Sampson NA, Hwang I, Kessler RC. Dropout from outpatient mental health care in the united states. Psychiatr Serv2009; 60(7): 898-907. 23- Wang PS, Berglund P, Kessler RC. Recent care of common mental disorders in the United States. $J$ Gen Intern Med2000; 15(5): 284-92.

24- Reynolds DJ. Premature termination: the patients perspective. [Dissertation]. Ohio, Cincinnati: University of Cincinnati, College of Arts and Sciences, Department of Psychology; 2001.

25- McCallum M, Piper WE, Joyce AS. Dropping out from short-term group therapy. Psychother 1992; 29(2): 206-15.

26- Sterling RC, Gottheil E, Weinstein SP, Shannon DM. Psychiatric symptomatology in crack cocaine abusers. $J$ Nerv Ment Dis1994; 182(10): 564-69.

27- Persons JB, Burns DD, Perloff JM. Predictors of dropout and outcome in cognitive therapy for depression in a private practice setting. Cognitive Ther Res1988; 12(6): 557-75.

28- Garfield SL. Research on client variables in psychotherapy. In: Bergin AE, Garfield SL, eds. Handbook of psychotherapy and behavior change. 4th ed. New York: Wiley and Sons; 1994.

29- Greenspan M, Kulish NM. Factors in premature termination in long-term psychotherapy. Psychotherapy (Chic) 1985; 22(1): 75-82.

30- Taylor L, Kaminer D, HardyA. Risk factors for premature termination of treatment at a child and family mental health clinic. $J$ Child Adolesc Ment Health2011; 23(2): 155-64

31- Jung SI, Serralta FB, Nunes MLT, Eizirik CL. Beginning and end of treatment of patients who dropped out of psychoanalytic psychotherapy. Trends Psychiatry Psychother2013; 35(1): 181-90.

32- Hampton-Robb S, Qualls RC, Compton WC. Predicting first-session attendance: the influence of referral source and client income. Psychother Res2003; 13(2): 223-33.

33- Liu-Siefert H, Adams DH, Kinon BJ. Discontinuation of treatment of schizophrenia patients is driven by poor symptoms response: A pooled posthoc analysis of four atypical antipsychotic drugs. $B M C$ Med2005; 3: 21.

Copyright $($ C 2016 ASP Ins. This open-access article is published under the terms of the Creative Commons Attribution-NonCommercial 4.0 International License which permits Share (copy and redistribute the material in any medium or format) and Adapt (remix, transform, and build upon the material) under the Attribution-NonCommercial terms. 